\title{
Digitalization as a Key Tool for Implementing Industry 4.0 in SMES
}

\author{
MGT. Gibran Aguilar Rangel*, Dr. Josefina Morgan Beltran \\ Universidad Autonoma de Queretaro Cerro de las Campanas s/n C.P. 76000 Queretaro Mexico \\ *Corresponding Authors: MGT. Gibran Aguilar Rangel, Universidad Autonoma de Queretaro Cerro de \\ las Campanas s/n C.P. 76000 Queretaro Mexico
}

\begin{abstract}
The fourth industrial revolution has been one of the most discussed topics at the industrial and business level, especially when it comes to innovation issues, although it originally arose in Germany, throughout the world it has been given impetus both from the industrial side, as well as academic and political, being the subject of conferences, summits and publications that discuss advantages or the technologies that comprise it, although until now those that have been most interested in implementing it have been large companies.
\end{abstract}

When talking about Industry 4.0, one of the most mentioned barriers to entry or disadvantages is invariably the high cost of implementing the different technologies required to be a part of it, it is this barrier that keeps SMEs or small and medium businesses.

This article presents an argument on how small and medium-sized companies can enter Industry 4.0 through the simplest steps of digitization, without making a large investment and what are the results they could expect from this, analyzing in the first instance, why it matters that this type of companies join this trend and not just large companies, followed by what digitization is and how to join it.

Key words: Industry 4.0, digitalization, SMEs, cloud computing.

Abbreviations: SMEs: Small and medium sized companies, ERP: Enterprise resource planning.

\section{INTRODUCCIÓN}

A few years after the introduction of Industry 4.0 as one of the pillars of future technological development in industrialized countries, its adoption has not been as expected, especially if one takes into account that it is considered the fourth industrial revolution, and the previous industrial revolutions had not been so carefully planned that they included road maps in various countries. This does not mean that the idea itself is being a failure, there are many countries that continue to promote the idea, as well as large companies that have already implemented the basic principles throughout their organization or in key parts and that offer assistance to others. companies (Siemens for example offers the Industry 4.0 live tour).

The problem lies in the smaller companies, which paradoxically make up the majority of companies globally, although they are not the ones that generate the most income, they do form an important part within the supply chain of any country. Previous industrial revolutions were an advantage for the company who would adopt it in the first instance or better adapt to the technological changes that the industrial revolution brought with it. This is no longer so true in this latest change, since few companies work individually.

The cause of this lies in globalization, which has allowed companies to expand, distribute their products, lower costs and overall generate more wealth than ever before in history, but it also leaves companies and countries dependent on economic decisions. and policies of other players, including decisions on health matters, as demonstrated by the 2020 health contingency. In this note. it is logical that Germany was the creator of the term industry 4.0 and one of its biggest promoters, since one of the most valuable national brands is SAP, an ERP that works better if a network of companies has it, not just one.

Industry 4.0 works in a similar way, its greatest strength does not lie, as many believe, in the automation of processes, but in the digitization of them, and the speed of response. More than a 
machine doing things automatically, industry 4.0 presents a panorama in which the production process can be known at each step, and decisions can be made immediately, so an order could be altered long before it becomes waste, whether it's changing part specifications, delaying or speeding up components, changing the delivery route, all of this done centrally without having to go to a specific location. In this process several technologies intervene, cloud computing, internet of things, data analysis, just to mention those that are key, but it is not feasible for a producer to control their entire supply chain, in order to achieve this decision-making power based on data and information analysis it is required that all companies within said supply chain have a certain level of digitization, if a link in that chain does not meet the standards, it cannot be carried out.

This article will begin by describing what is understood as a small and medium-sized company, it will talk about the supply chain and its importance in the global environment, then the subject of key technologies to start the digitization that is cloud computing will be discussed. and how its implementation in smaller companies could lead them not to be excluded from Industry 4.0 without requiring a strong investment, ending with a reflection on where digitization is directed and why it is a key element in the adoption of this trend

\section{DEVELOPMENT}

\subsection{Classification of Companies}

There are different ways to classify a small or medium-sized company as such, it can be by the number of employees (which is the way to classify it used by the OECD), or by the income it generates, although the trend may go more to this second option, since as automation reduces the number of employees to keep a company in operation, it will be more difficult to justify why a company that generates more than 100 million Mexican pesos in sales per year should be considered small or even micro by your employee number. The European Union and countries Latin America as in the case of Mexico, use a mixed rating classification in which considers the number of employees and revenue of the company. In general, a company with fewer than 250 employees will be considered medium and a micro company can be as small as 1 person
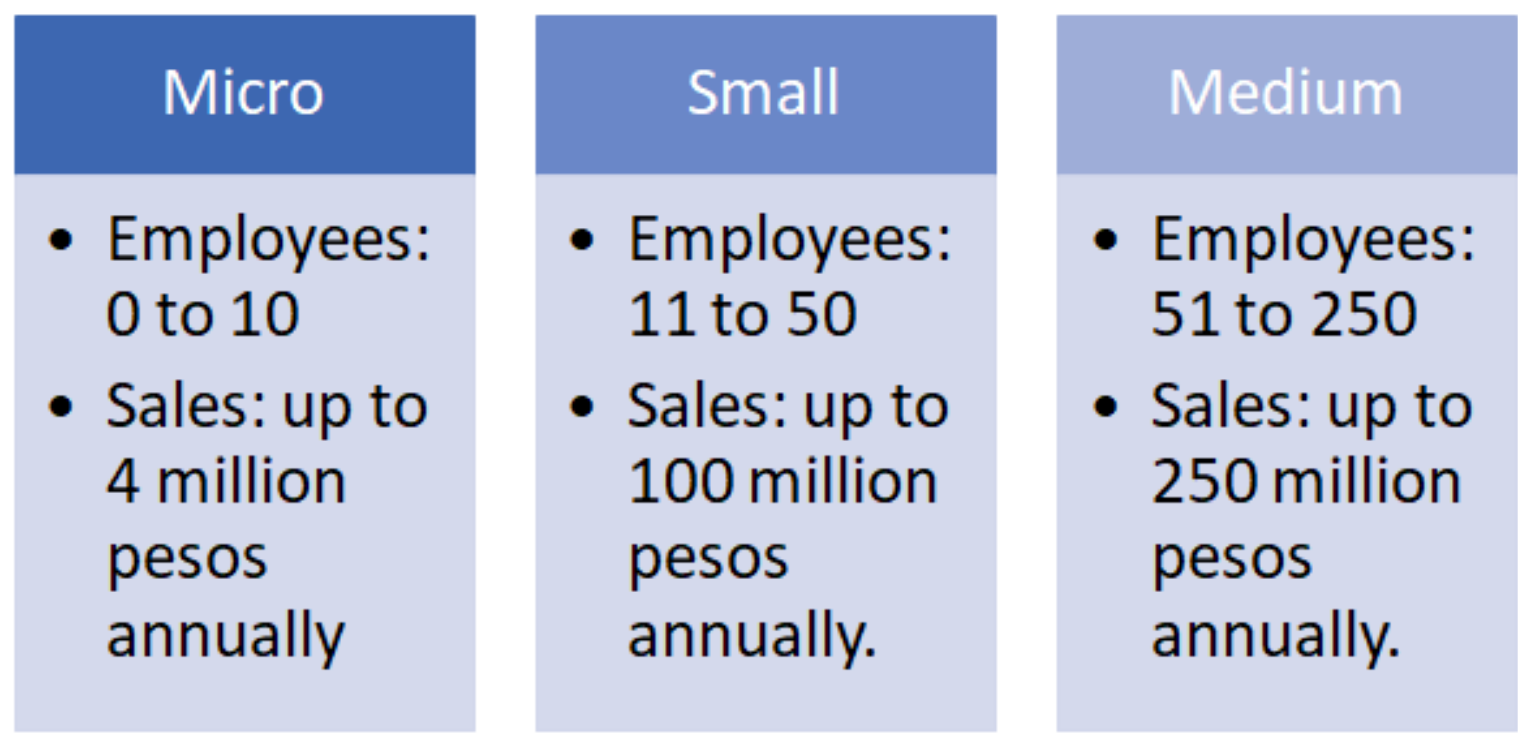

Source: own construction based on DOF (2009)

Small and medium-sized companies have unique characteristics that make them very different from large companies, decision-making and therefore their potential growth, will be determined many times by the beliefs and personal character of the owner or manager (Sarwoko\&Frisdiantara, 2016) this may delay the adoption of certain technologies but at the same time gives them some flexibility when it comes to adaptation, it does not require to go through overly rigorous processes as the bigger companies.

\subsection{Supply Chain}

With the arrival of globalization, large companies had access to suppliers and customers in remote markets, so it became a necessity to have a network of facilities and a distribution network that would 
allow the supply and distribution of materials, their transformation into semi-finished products and / or end products and distribution to the customer (Ganeshan and Harrinsson , 1995). This is known as the supply chain, meaning that a company no longer depends on its individual efforts, but also on the performance of its allies, on how the functional activities that are developed along the product flow channel, from raw material to final product, these have to be carried out correctly and there has to be constant communication between the companies.

The existence of a supply chain also implies that there is a risk, part of mitigating this risk consists on not depending on a single supplier for any of the parts of the process, this is to avoid at a certain degree some of the main risks, this is in part what makes small and medium-sized companies part of the supply chains of large companies, they divide the workload between various companies, often in different regions, in order to add additional insurance to hurdles such as the climate, internal politics, among others. There are various studies on how to deal with possible disruptions in the supply chain and the best way to work it, one of the most accepted ways has to do with the early identification of risks (Hamdi, Tarik, \&Bahli, 2020) which is achieved by obtaining information, in this same study it is mentioned that one of the great problems may be the timely collection appropriate information.

\subsection{Digitization}

To speak of industry 4.0 is to speak of the digitization process or of moving from the physical plane to the digital plane, or the union between the two, as it occurs in cyber-physical systems, but what is understood as digitization? A comprehensive way of looking at it is as "...the phenomenon of transforming analog data into digital language (digitization), which, in turn, can improve business relationships between clients and companies, giving added value to the economy and society in general." (Reis, Amorim, Melao, Cohen, \& Rodrigues, 2020 p. 448 ) .

Understanding what digitalization is, at its core and in its simplest form,we can understand that it does not necessarily mean all the cost and effort to make digital twins for factories or to automate all the processes, you can start with something as simple as using a cloud storage service that synchronizes the information.

Cloud computing, which is the appropriate term for the process described above, broadly consists of using servers (whether internal or external) and network connections to store data and make it accessible at all times, anywhere in the world. This must be accompanied by cybersecurity and data protection processes in order to safeguard confidential information, but this type of protection is offered by services as common as Dropbox or Google Drive that can have free versions.

The process of introducing small and medium-sized companies to Industry 4.0 does not have to be an expensive investment that leads them to rethink their entire business process and go through a monthlong restructuring that may not yield economic benefits in the short or medium term. You can start with something as simple as analyzing your information flow and data recording and transfer it to the digital plane, using a cloud computing service, which would have the added benefit of being able to have the information accessible outside the company.

This first step may seem not so important, but its effect has to do not only with what happens in the company but in the supply chain of which it is part. Implementing cloud computing processes, especially in areas sensitive to delays such as production, shipments, among others, will allow customers to better monitor their products and make decisions based on real-time information, partially mitigating the risks inherent to the supply chain. The company that implements it, for its part, on the customer's side, will be able to generate greater certainty, improve communication processes and anticipate customer needs, if the information relationship is reciprocal. For their internal processes, being able to access this data, have it organized and in a single location and updated in real time, it could drastically improve the productivity and control.

The steps that are proposed for companies to start their digitization process would be as follow:

1. Observation: The basic part of the process starts from transferring from analog to digital, how are failures noted in a process? What is the way to notify a delay?

2. Analysis: What processes are constantly generating data? Which of those processes could you start collecting data through a tablet or app? 
3. Quiz: What is the right service for your business needs? Who do you plan to share the information with? Do you generate data that requires large storage or low-load data?

4. Discussion: What system do your customers or business partners use? What compatibilities do you require?

5. Pilot test and feedback: has the data collected been useful? How friendly is the interface for your employees?

\section{CONCLUSION}

The term industry 4.0 can create confusion since it is not a question of a particular technology or a specific process, it is a cluster of technologies, a change in the way of doing things, which has at its center the process of going from analog to digital, but more than that, changing the way we share information.

For the fourth industrial revolution to really take off, a change in mentality is required as to what a company must comply with to enter this scheme, if small and medium-sized companies do not start their digitization process, large companies themselves will not be able to promote and maintain this trend. The 2020 health contingency showed what can happen when the entire supply chain is disrupted, however brief this disruption may be, it can stop entire economies. It does not matter how automated a factory is or how sophisticated the processes of a large manufacturer are, thanks to globalization, they continue to depend on a series of suppliers that in turn depend on other suppliers and at some point in that chain, there can be a weak link that causes the break and stops the whole process.

It is not that one should not seek in the future to integrate all the other technologies that are part of industry 4.0, but initially it should be sought that all companies are at the same base level of digitization

\section{REFERENCES}

[1] Ganeshan, R., Harrisson, T. (1995). An Introduction to Supply Chain Management.

[2] Hamdi, A., Tarik, S., \& Bahli, B. (2020). Volume 40, Issue 4 Facing supply chain disruptions : enhancers of supply chain resiliency, 40(4).

[3] Reis, J., Amorim, M., Melao, N., Cohen, Y., \& Rodrigues, M. (2020). Digitalization: A literature review and research agenda. Springer Nature, (March). https://doi.org/https://doi.org/10.1007/978-3-030-436162_47

[4] Sarwoko, E., \& Frisdiantara, C. (2016). Growth Determinants of Small Medium Enterprises (SMEs). Universal Journal of Management, 4(1), 36-41. https://doi.org/10.13189/ujm.2016.040105

\section{AUTHORS' BIOGRAPHY}

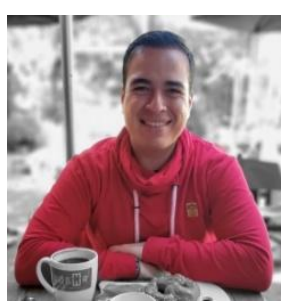

Gibrán Aguilar Rangel, Master in Technology Management, currently completing a Doctorate in Technology Management and Innovation. He is a professor at the Autonomous University of Queretaro, teaching in master's and bachelor's degrees of the FCA of the UAQ with the lines of Mathematics, Finance and Technology Management and Innovation. His previous experience includes working as a senior consultant for one of the top consulting firms worldwide, in the business risk area.

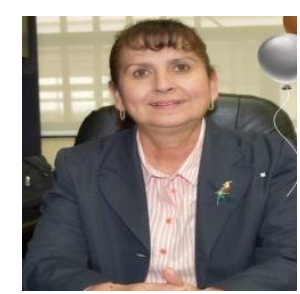

Josefina Morgan Beltrán, Doctorate in Administration and Master in Administration and Finance from the Autonomous University of Querétaro, with Post-doctorates in Education-Management of Educational Institutions and in Education (in progress). She is a Full Time Professor and Researcher, teaching in the doctorate, master's and bachelor's degrees of the FCA of the UAQ, with the lines of Culture, Finance, Competitiveness, Globalization, Certifications, Leadership, Innovation and Knowledge Management. She is a member of the SNI, Level 1 (CONACYT), PROMEP profile (SEP) and ANFECA Certification. He is a member of the Academic Body 114 "Competitive Management" of the UAQ Faculty of Accounting and Administration, of the International Network of Researchers in Organizational Competitiveness, of the Association of Work Psychology, of the Association of Accounting and Administration 
Professors and of the College of Public Accountants. She is currently Head of the Division of Graduate Studies and Research of the FCA of the UAQ.

Citation: MGT. Gibran Aguilar Rangel*, Dr. Josefina Morgan Beltran. "Digitalization as a Key Tool for Implementing Industry 4.0 in SMES" International Journal of Managerial Studies and Research (IJMSR), vol 9, no. 6, 2021, pp. 27-31. doi: https://doi.org/10.20431/2349-0349.0906003.

Copyright: () 2021 Authors. This is an open-access article distributed under the terms of the Creative Commons Attribution License, which permits unrestricted use, distribution, and reproduction in any medium, provided the original author and source are credited. 